\title{
Assessment of left ventricular function after myocardial infarction
}

\author{
D. J. E. Taylor ${ }^{1}$ and P. G. F. Nixon \\ From the Cardiac Department, Charing Cross Hospital, London
}

The low frequency sounds and movements of the heart at the apex were recorded in $5 I$ cases of acute myocardial infarction. Good correlation was found between the changes recorded, the clinical and radiological assessment of left heart function, and the left heart pressures. The technique is painless, safe, reproducible, and we believe gives useful additional information as to the function of the left ventricle after acute myocardial infarction.

- In acute myocardial infarction the impairment of left ventricular function depends upon the severity of the acute injury and the amount of disease already present. The severity of the acute injury is usually assessed indirectly from

- the electrocardiogram and enzyme changes, and the impairment of left ventricular func-

2. tion from the presence or absence of 'failure'. 'Failure' is an unsatisfactory term because its definition and implications are open to dispute, and small changes either of improvement or deterioration are not readily apparent.

- Left heart catheterization is rarely practical, ethical, or desirable.

- Recording the chest wall pulsations over the apex of the left ventricle with a simultaneous phonocardiogram and electrocardiogram is an investigation which can be made at the bedside. It has been shown to give useful information about heart function in primary myocardial disease (Shah, Gramiak, and

- Kramer, 1968), valvular heart disease (Nixon and Wooler, 1963; Fleming, 1968; Epstein et -al., 1968), hypertension (Beilin and Mounsey, I962), and ischaemic heart disease (Benchimol and Grey Dimond, 1962).

The purpose of this paper is to describe the findings from a study of $5 \mathrm{I}$ cases of acute - myocardial infarction and to correlate the information with the results of left heart catheterization in 13 cases of coronary heart disease. The investigation suggests that the technique is a simple and useful method for assessing day-by-day changes in left ventricular func-

- Received 31 December 1971.

1 Present Address: Kent and Canterbury Hospital, Ethelbert Road, Canterbury, Kent. tion. It also throws light on the significance of the fourth heart sound in coronary heart disease.

FIG. I Diagrammatic representation of apex displacement curves showing normal and the 4 groups of abnormal recordings.
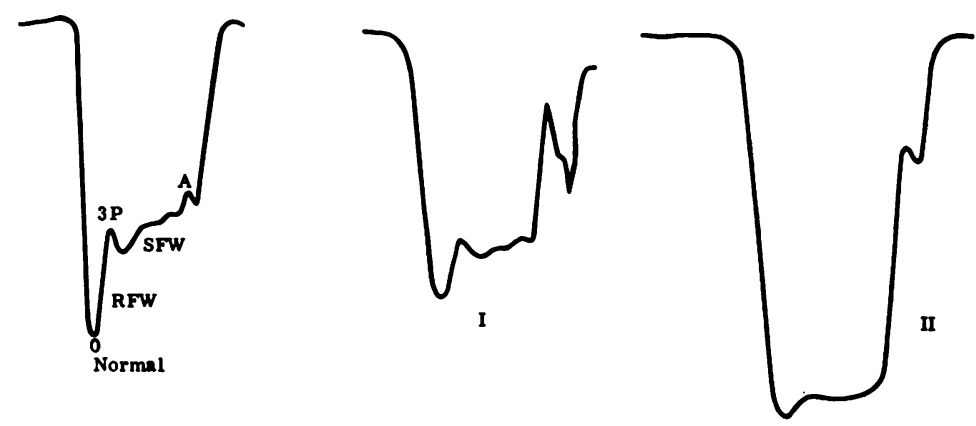

TYPES OF DIASTOLIC MOVEMENTS RECORDED
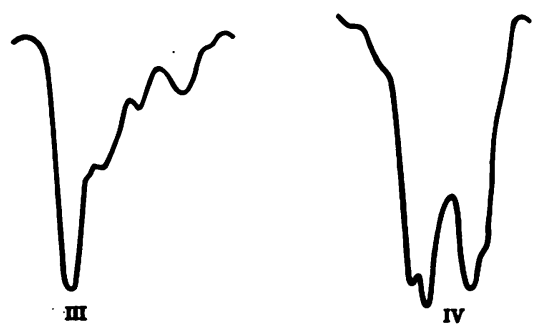
FIG. 2 Normal pattern. adc $=$ apex displacement curve; $R F W=$ rapid filling wave; $F=$ rapidly filling peak; $S F W=$ slow filling wave; $A={ }^{\prime} a$ ' wave of atrial contraction.

FIG. 3 Abnormal pattern; Group I. $3 P=$ rapidly filling peak.

FIG. 4 Abnormal pattern: Group I. $O$ in low frequency phonocardiogram channel= opening snap.
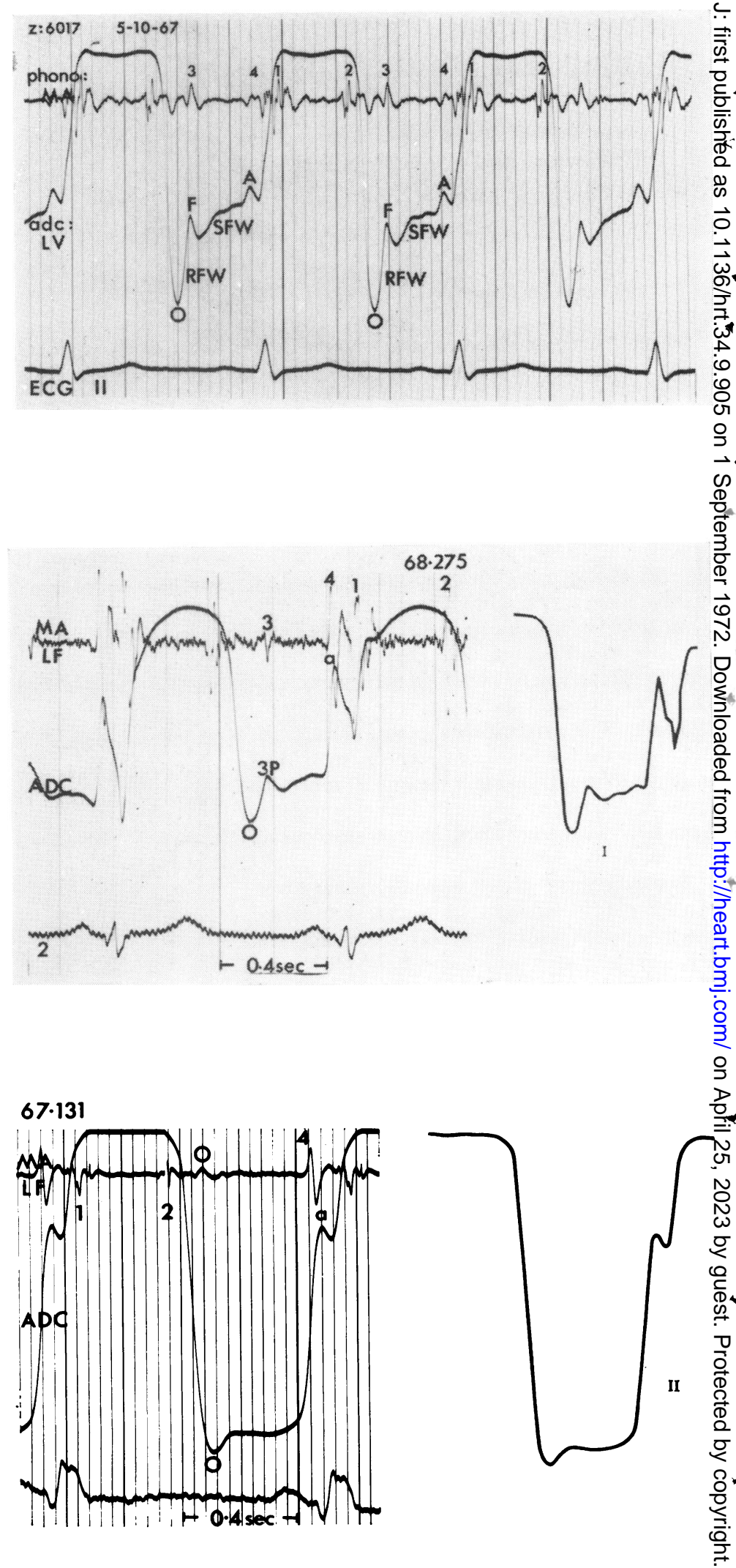
FIG. 5 Abnormal pattern: Group 3.
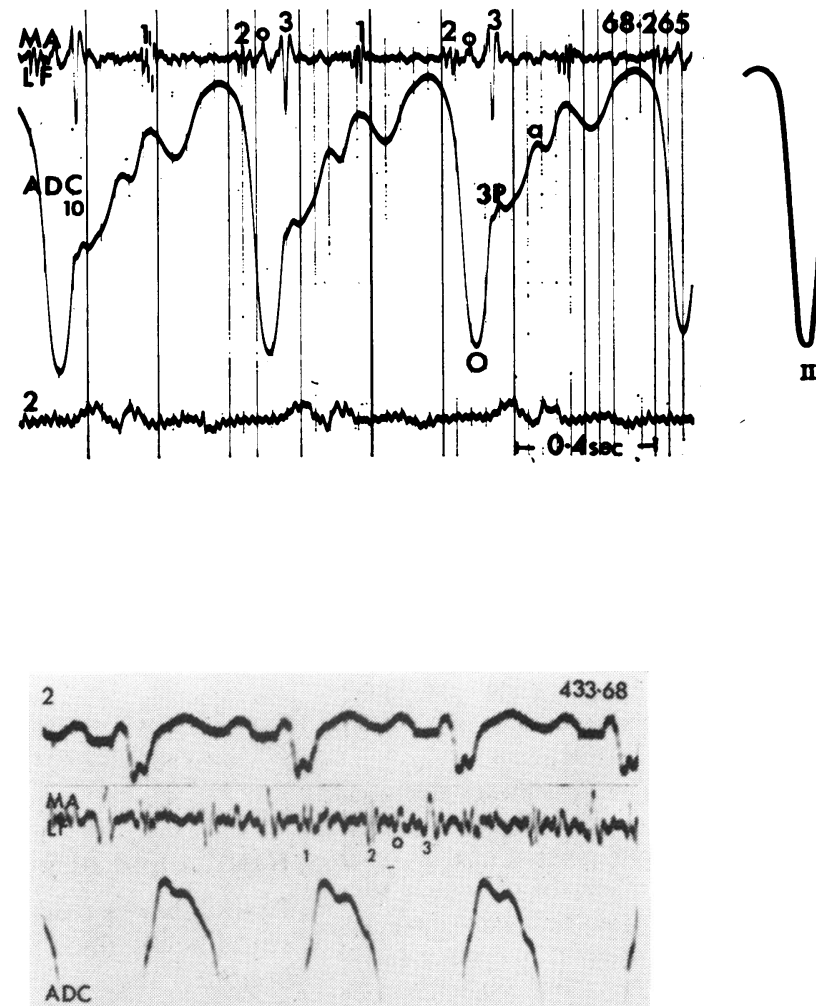

FIG. 6 Abnormal pattern: Group 4. Simultaneous recording (reading down) - electrocardiogram lead II, phonocardiogram, apex displacement curve, left atrial pressure, electrocardiogram lead II.
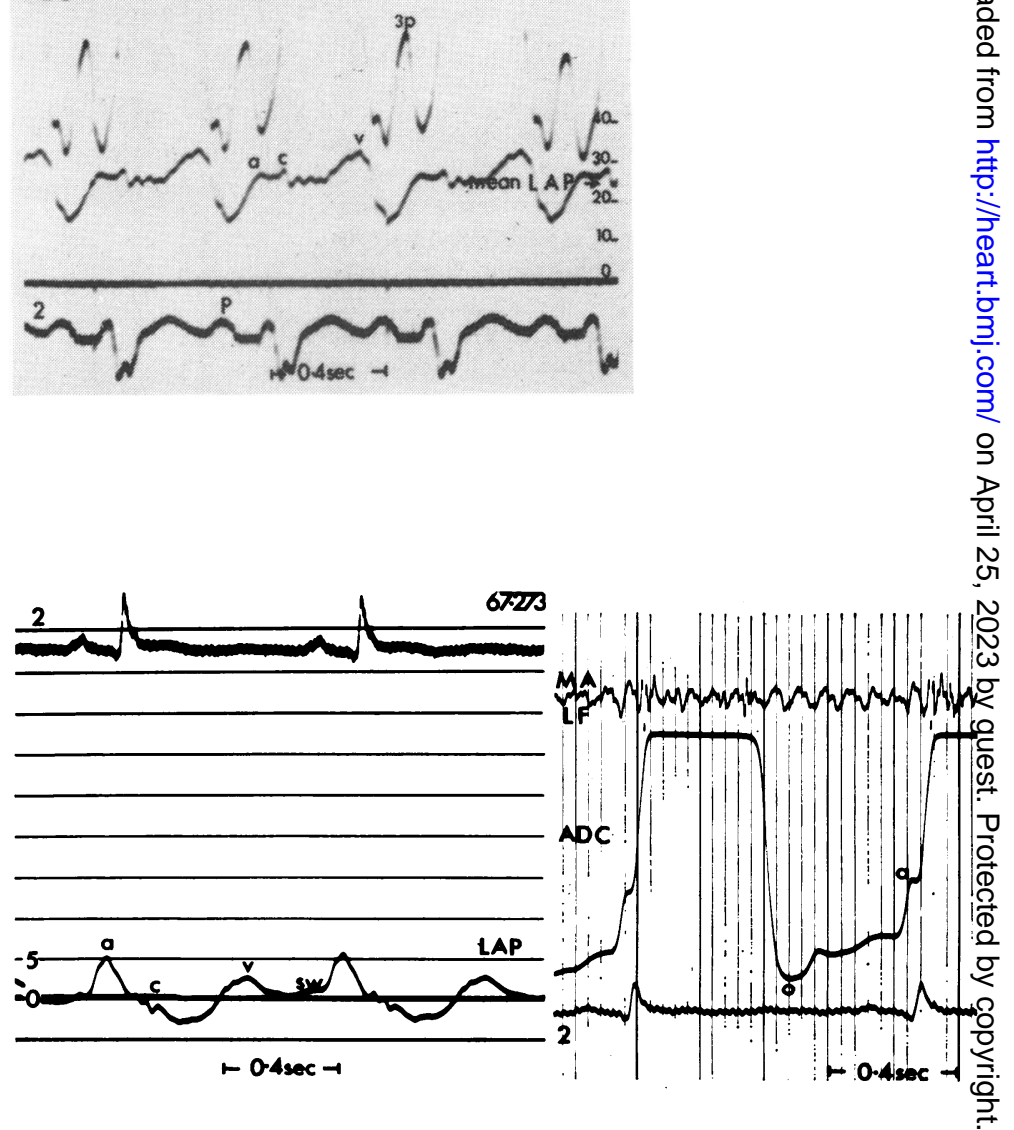

FIG. 7 Left atrial pressure in Group I, each line representing $5 \mathrm{mmHg}$, and electrocardiogram lead II. Apex displacement curve from the same patient. 


\section{Subjects and methods}

The patients were 5I consecutive cases of acute myocardial infarction admitted to the intensive care ward, where a uniform pattern of clinical observation, investigation, and treatment could be followed. They were treated initially by a sleep regimen (Nixon et al., 1968) and digitalis and diuretics were given as required. The diagnosis of acute myocardial infarction was made from serial electrocardiograms and enzyme changes.

The recordings of the heart sounds and pulsations were made on the second and third day of admission and thereafter at weekly intervals, with the patient usually lying in the left lateral or semilateral position in arrested expiration. The site was the area of maximum outward pulsation of the apex of the left ventricle as defined by Mackenzie (1902). The aspect of motion of the chest wall selected for study was displacement, and this was recorded, together with the low frequency phonocardiogram, with a previously described (Nixon, Hepburn, and Ikram, 1964) modification of industrial apparatus.

With this apparatus it is possible to use great amplification without distorting the wave form, and this allows the diastolic portion of the curves to be selected for close study. In obtaining tracings from several thousand subjects over a ro-year period, a relatively small number of basic patterns of left ventricular diastolic wave form were encountered. These patterns may be seen in Fig. I, from which cases of mitral valvar disease and chronic left ventricular aneurysm have been excluded. It should be noted that the patterns are not determined by the nature of the disease affecting the left ventricle but by the severity of the heart disease. Thus, movement from a group 2 pattern to a group 3 pattern is associated with the onset of heart failure. If treatment were given, movement back to group 2 would indicate that improvement was taking place, while movement to group 4 would reveal continuing deterioration. The aetiology of the heart disease could not be deduced from the wave form. Some knowledge of the patient's history might be required to distinguish a group I from a group 3 pattern.

The normal in Fig. 2 is recorded as physiological because it is the characteristic finding in the absence of any recognizable heart disease. In essence, the ' $a$ ' wave and the rapid filling wave bear a more or less constant relation to each other in health, both increasing or decreasing in size together with variations in heart activity. However, in pathological situations such as ischaemic heart disease without congestive failure the ' $a$ ' wave enlarges and the rapid filling wave diminishes in size as shown in Fig. 3 and 4. When congestive cardiac failure supervenes, the ' $a$ ' wave diminishes and the rapid filling wave enlarges (Fig. 5). In further deterioration in function the ' $a$ ' wave virtually disappears (Fig. 6). There is thus a waxing and waning of the ' $a$ ' wave associated with progressive deterioration in left ventricular function.

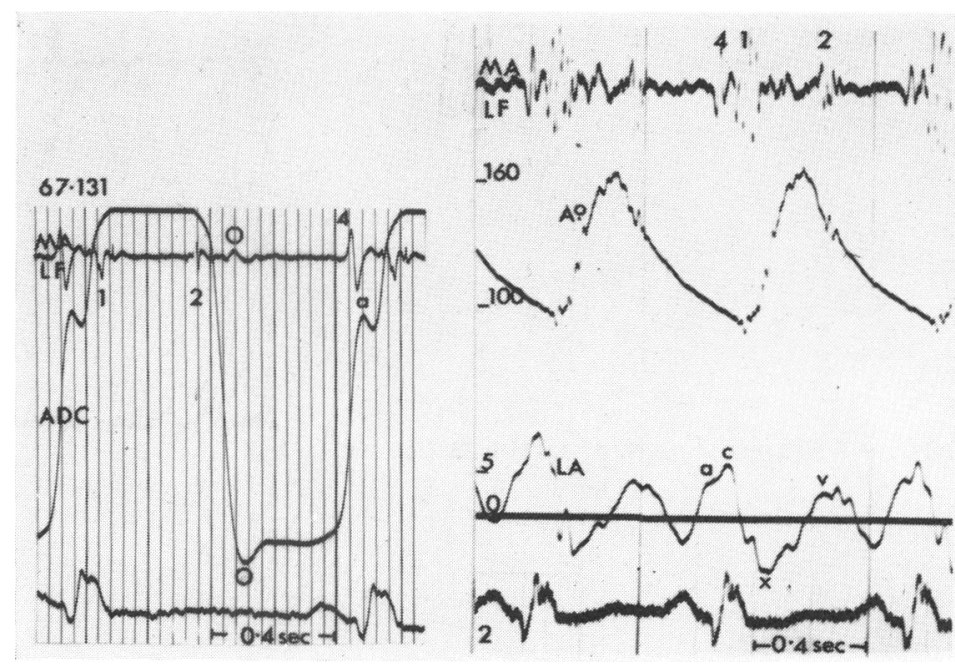

FIG. 8 Left atrial pressure in Group 2. $A^{\circ}=$ aortic pressure; $L A=$ left atrium.

\section{Results and discussion}

In the present study of $5 \mathrm{I}$ cases, useful records could be obtained in 49. Normal records were obtained in 2 and abnormal records in 47. There were 31 cases in group $I$, IO cases in group 2, 4 cases in group 3, and 2 cases in group 4.

The clinical signs of heart failure were not found in those patients exhibiting a group $I$ or 2 pattern, but were present in those of

\section{FIG. 9 Left atrial pressure in Group 3.}

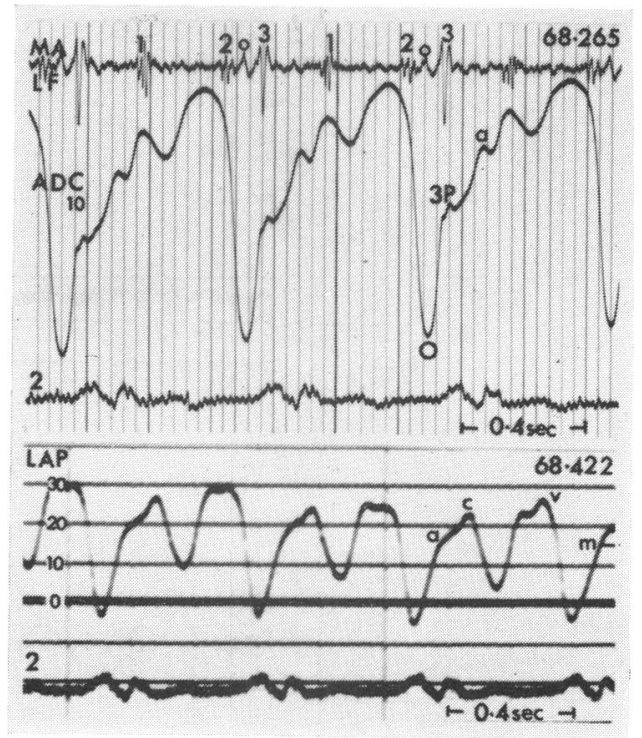




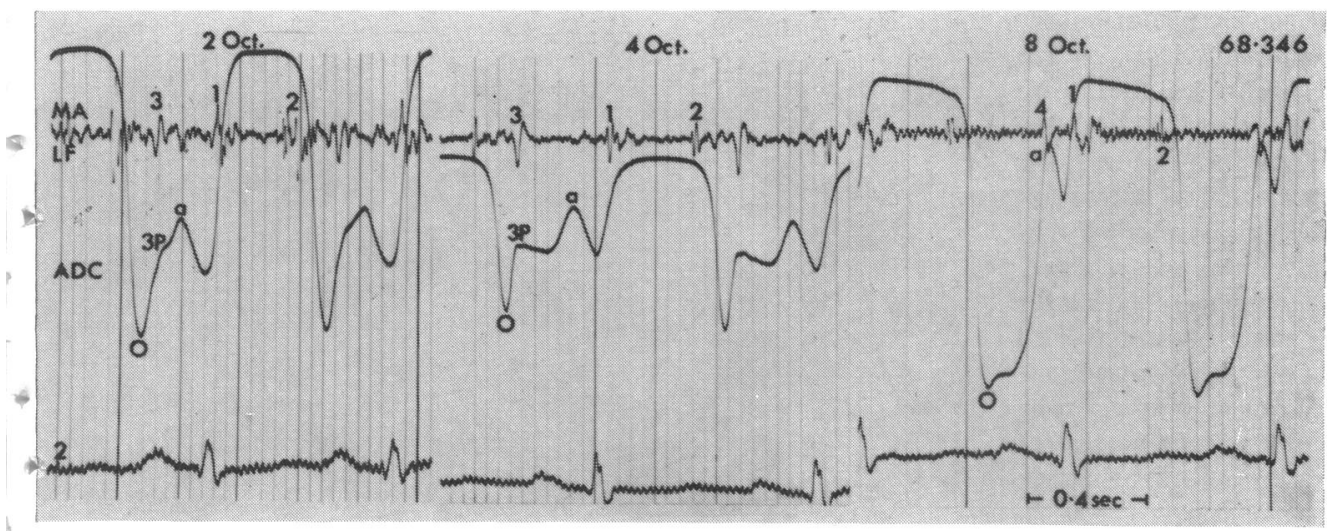

F I G. Io Changing pattern over days. Group 4 pattern - 2nd October. Group 3 pattern - 4 th October. Group 2 pattern - 8th October. $\downarrow$

group 3 and 4. The cardiothoracic ratio on radiological examination was less than $2: 1$ and the lung fields clear in groups $I$ and 2, but there was always cardiac enlargement in groups 3 and 4, with evidence of raised pul-

$\checkmark$ monary venous pressure in some. There appeared to be a good correlation between the tclinical and radiological findings and the gradings found on apex recording (Table).

These findings were supported by the transseptal left heart recordings that were made. The 7 cases in group I (Fig. 7) and 2 cases in - group 2 (Fig. 8) had mean left atrial pressures below Io mmHg. The 2 cases in group 3 had 2 left atrial mean pressures between II and 20 mmHg (Fig. 9) and the 2 cases in group 4 left atrial mean pressures higher than 21 mmHg (Fig. 6).

This information suggests that movement from group $I$ to 2 is unaccompanied by noteworthy change in mean left atrial pressure,

- but deterioration to group 3 is associated with clear-cut abnormality of the left atrial mean pressure. In group 4 the abnormality is severe. In myocardial infarction the deterioration

TABLE

\begin{tabular}{lrlll}
\hline & No. & $\begin{array}{l}\text { Cardio- } \\
\text { thoracic } \\
\text { ratio }\end{array}$ & $\begin{array}{l}\text { Clinical } \\
\text { signs of } \\
\text { failure }\end{array}$ & $\begin{array}{l}\text { Left atrial } \\
\text { pressure } \\
(\mathrm{mmHg})\end{array}$ \\
\hline Group I & $3 \mathrm{I}$ & $<50 \%$ & Absent & $<\mathrm{IO}$ \\
Group 2 & 10 & $<50 \%$ & Absent & $<10$ \\
Group 3 & 4 & $>50 \%$ & Present & $10-20$ \\
Group 4 & 2 & $>50 \%$ & Present & $>21$ \\
Normal & 2 & & & \\
Poor record & 2 & & & \\
\hline Total & 51 & & & \\
\hline
\end{tabular}

from group 2 to 4 and its reversal with treatment might take place over a period of hours or days (Fig. 10). This contrasts with, for example, aortic valvar disease or cardiomyopathy where the time scale is measurable in months and years.

The inspection of the low frequency phonocardiogram trace showed fourth heart sounds in two-thirds of the patients (Fig. II). All

FIG. II Apex cardiogram and phonocardiogram results in $5 I$ cases.

\begin{tabular}{|c|c|c|c|c|}
\hline & No. & $\begin{array}{c}\text { 4th } \\
\text { SOUND }\end{array}$ & $\begin{array}{c}\text { 3rd } \\
\text { sOUND }\end{array}$ & o.s. \\
\hline GROUP I & 31 & 22 & 3 & 4 \\
\hline GROUP II & 10 & 7 & 2 & 5 \\
\hline GROUP III & 4 & 2 & .1 & 1 \\
\hline GROUP IV & 2 & - & 2 & - \\
\hline NORMAL & 2 & - & - & - \\
\hline POOR RECORDS & 2 & - & - & - \\
\hline TOTAL & 51 & $31(60 \%)$ & $8(15 \%)$ & $10(19 \%)$ \\
\hline
\end{tabular}


had abnormally large ' $a$ ' waves. Abnormal ' $a$ ' waves failed to be accompanied by fourth heart sounds under two conditions. In Fig. I2 the atrial contraction is slow and of low frequency, and thus may not produce audible vibrations, and in Fig. 13 the atrial contraction is so very close to isometric contraction that the fourth and first sounds are almost merged. This may explain the lower figure recorded for fourth sounds than other observers noted (Hill et al., 1969). We felt that the third sound gallop rhythm represented raised end-diastolic pressure and indicated more serious deterioration in function than was reported by Stock (1966).

An interesting finding was a sound transient at that time in diastole which in mitral valve disease would be designated an opening snap; its significance in this context is not clear, but it was noted in 19 per cent of cases.

Our thanks are due to Miss I. Wood and Miss Anne Smith for technical assistance and to the Department of Medical Photography, Charing Cross Hospital, for the illustrations.

\section{References}

Beilin, L., and Mounsey, P. (1962). The left ventricular impulse in hypertensive heart disease. British Heart fournal, 24, 409.

Benchimol, A., and Grey Dimond, E. (1962). The apex cardiogram in ischaemic heart disease. British Heart fournal, 24, 581.

Epstein, E. J., Coulshed, N., Brown, A. K., and Doukas, N. G. (1968). The 'a' wave of the apex cardiogram in aortic valve disease and cardiomyopathy. British Heart fournal, 30, 591.

Fleming, J. S. (1968). The assessment of failure in aortic stenosis from the diastolic movements of the left ventricle. American Heart fournal, 76, 235.

Hill, J. C., O'Rourke, R. A., Lewis, R. P., and McGranahan, G. M. (1969). The diagnostic value of the atrial gallop in acute myocardial infarction. American Heart fournal, 78, 194.

Mackenzie, J. (1902). The Study of the Pulse. Y. J. Pentland, Edinburgh.

Nixon, P. G. F., Hepburn, F., and Ikram, H. (1964). Simultaneous recording of heart pulses and sounds. British Medical fournal, , $1,1169$.

Nixon, P. G. F., Taylor, D. J. E., Morton, S. D., and Bromfield, M. (1968). A sleep regime for acute myocardial infarction. Lancet, $\mathbf{r}, 726$.

Nixon, P. G. F., and Wooler, G. H. (1963). Phases of diastole in various syndromes of mitral valvular disease. British Heart fournal, 25, 393.

Shah, P. M., Gramiak, R., and Kramer, D. H. (1968). Determinants of atrial $\left(\mathrm{S}_{4}\right)$ and ventricular $\left(\mathrm{S}_{3}\right)$ gallop sounds in primary myocardial disease. New England fournal of Medicine, 278, 753.

Stock, E. (I966). Auscultation and phonocardiography in acute myocardial infarction. Medical fournal of Australia, 1, ro6o.

Requests for reprints to Dr. D. J. E. Taylor, Kent and Canterbury Hospital, Ethelbert Road, Canterbury, Kent.

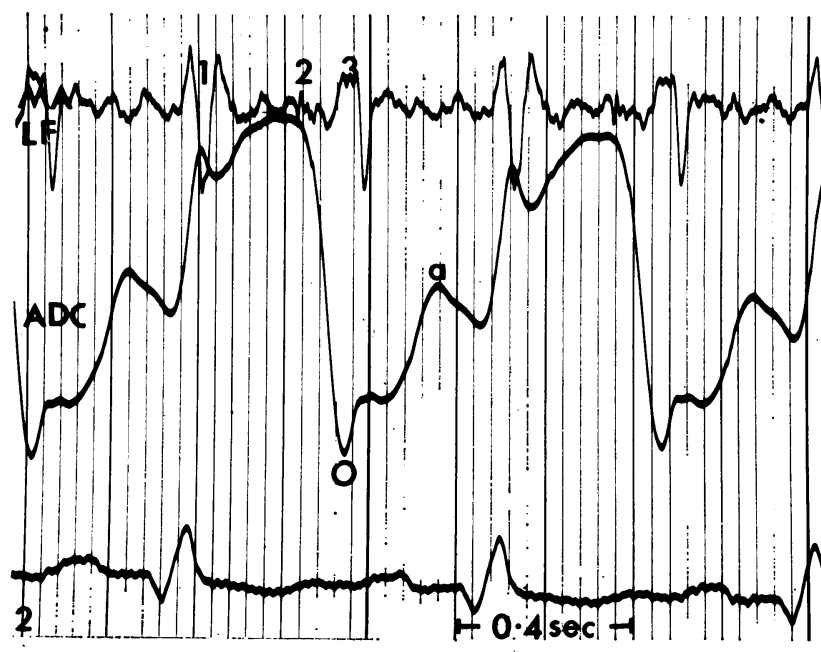

FIG. I2 Low frequency ' $a$ ' wave, no fourth sound.

FIG. I3 Atrial contraction close to isometric contraction.

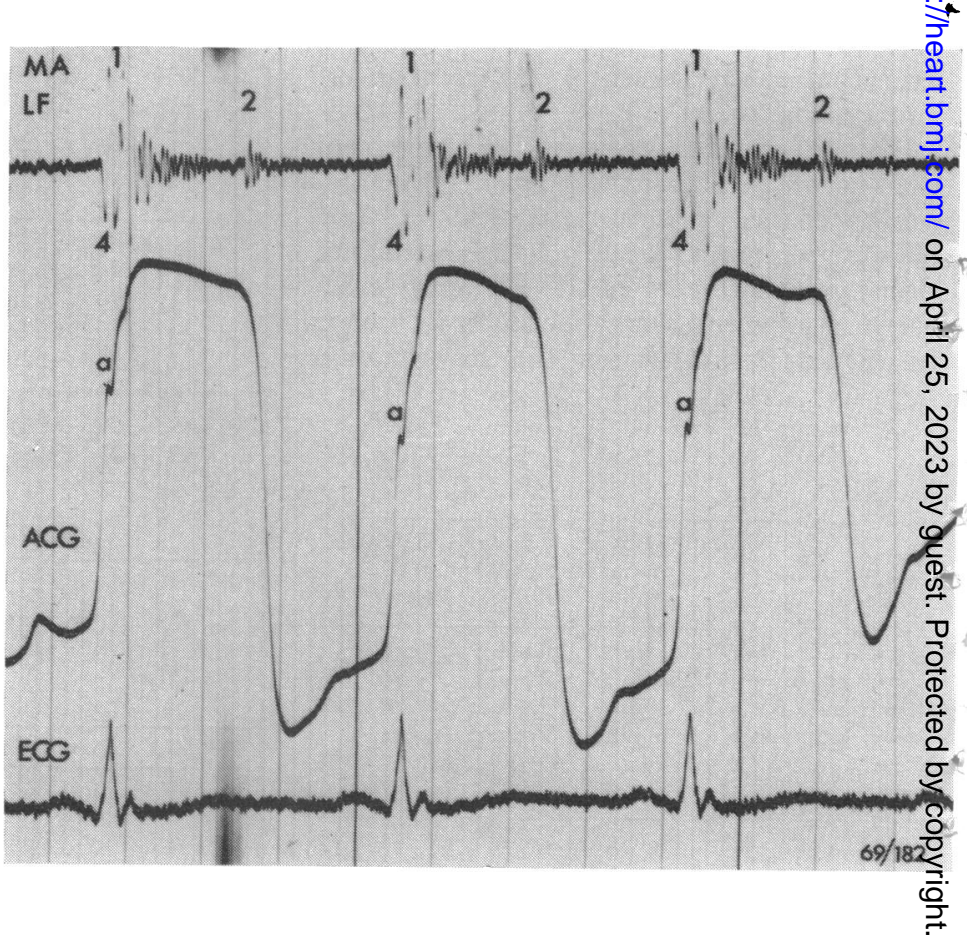

